Círculo de Lingüística Aplicada a la Comunicación ISSN: $1576-4737$

\title{
Vigo 2018: XIII Congreso Internacional de Lingüística Xeral
}

http://cilx2018.uvigo.gal/

O XIII Congreso Internacional de Lingüística Xeral (CILX2018) vaise celebrar na Universidade de Vigo do 13 ao 15 de xuño de 2018.

Trátase da décimo terceira edición dun evento que tivo a súa orixe en Valencia en 1994. Desde aquela, o CILX achegou un amplo e fecundo diálogo bienal sobre a investigación en Lingüística, con paradas en Granada (1996), Salamanca (1998), Cádiz (2000), León (2002), Santiago de Compostela (2004), Barcelona (2006), Madrid (2008), Valladolid (2010), Zaragoza (2012), Pamplona (2014) e Alcalá de Henares (2016).

O CILX2018 contará no seu programa con ponencias plenarias, comunicacións orais, paneis temáticos e pósteres, que abranguerán as diferentes áreas, metodoloxías e perspectivas teóricas relacionadas co estudo da linguaxe e as linguas

\section{Sección xeral de comunicacións e pósteres}

O CILX2018 admite comunicacións (20 minutos de presentación oral máis 5 de discusión) e pósteres con contidos relevantes para a Linguiística Xeral sobre calquera área, metodoloxía e perspectiva teórica relacionadas co estudo da linguaxe e as linguas.

O envío de resumos debe facerse exclusivamente a través do formulario creado para tal finalidade en EasyAbs: http://linguistlist.org/easyabs/cilx2018

Prazos son os seguintes:

- Data límite para a recepción de propostas: 1 de decembro de 201715 de decembro de 2017

- Comunicación de aceptación de propostas: 1 de febreiro de 2018

\section{Paneis temáticos}

Ademáis da sección xeral, en CILX2018 haberá tamén paneis temáticos sobre temas específicos. Algúns deles son de participación restrinxida, pero outros están abertos a propostas de participación. Consúltese a información de cada panel 


\section{Ponencias plenarias}

- Ofelia García (City University of New York): El translanguaging y el plurilingüismo: Convergencias y divergencias

- M. Antònia Martí (Universitat de Barcelona): Modelos de semántica distribucional

- Juan Carlos Moreno-Cabrera (Universidad Autónoma de Madrid): Lenguas de señas, historia de la lingüística y lingüística general 